\title{
Immunohistochemistry Was Not Performed
}

National Cancer Institute

\section{Source}

National Cancer Institute. Immunohistochemistry Was Not Performed. NCI Thesaurus.

Code C160382.

An indication that immunohistochemical testing was not performed during the study. 